Supporting Information for

\title{
Surfactant-free latex nanocomposites stabilized and reinforced by hydrophobically functionalized cellulose nanocrystals
}

Yefei Zhang ${ }^{\mathrm{a}}$, Han Yang ${ }^{\mathrm{a}}$, Nevin Naren ${ }^{\mathrm{a}}$ and Stuart J. Rowan ${ }^{\mathrm{a}, \mathrm{b}, \mathrm{c}^{*}}$

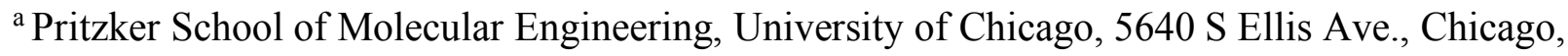
Illinois 60637, United States

${ }^{b}$ Department of Chemistry, University of Chicago, 5735 S Ellis Ave., Chicago, Illinois 60637, United States

${ }^{\mathrm{c}}$ Chemical and Engineering Sciences, Argonne National Laboratory, 9700 Cass Ave, Lemont, Illinois 60439, United States

*Corresponding authors email: stuartrowan@uchicago.edu

Table of Contents:

Page

S2 Percolation model.

S3 Coverage study.

S4 AFM height images of $m$-CNC-COOH and $M x G$-CNC-COOH.

S5 FTIR spectra of oxidized and hexyl-modified $m$-CNC-hexyl-COOH and $M x G$-CNChexyl-COOH.

S6 Elemental analysis and zeta potential study of functionalized CNCs.

S7 Loss modulus and tan $\delta$ of the latex films stabilized with SDS or hexyl CNCs.

S8 SEM images of the cross-sectional areas of latex films stabilized with SDS.

S9 Photographs of latex composite films stabilized with SDS coated CNC-COOH.

S10 Comparison of the size of latex parties, mechanical properties and the water swelling of the latex composite films stabilized with CNC-hexyl and SDS/CNC-COOH.

S11 DMA temperature sweep study of the latex composite films stabilized with CNC-hexyl and SDS/CNC-COOH.

S12 SEM images of the cross-sectional areas of latex films stabilized with SDS coated m$\mathrm{CNC}-\mathrm{COOH}$ and $\mathrm{MxG}-\mathrm{CNC}-\mathrm{COOH}$.

S13 Photographs of melt-pressed latex composite films stabilized with CNC-hexyl-COOH.

S14 DMA temperature sweep study of the latex films stabilized with SDS or m-CNC-hexyl$\mathrm{COOH}$ after melt pressing.

S15 Loss modulus and tan $\delta$ of the latex films stabilized with SDS or $M x G$-CNC-hexyl$\mathrm{COOH}$ after melt pressing.

S16 Photographs of latex composite films contain $13 \mathrm{wt} . \%$ of $m$-CNC and $M x G$-CNC.

S17 Loss modulus and tan $\delta$ of the latex composite films stabilized with $13 \mathrm{wt} . \%$ of $m$-CNC and $M x G$-CNC. 


\section{Percolation model:}

The Percolation model can be used to predict the storage modulus $E^{\prime}$ of the nanocomposites. This model assumes the rigid filler particles $\left(E_{r}^{\prime}\right)$ form a percolating network within the soft polymer matrix $\left(E_{s}^{\prime}\right)^{1,2}$ The level of reinforcement of the CNCs in the nanocomposite is a function of the volume fraction $\left(X_{r}\right)$, aspect ratio (AR) and the modulus of the rigid filler particles $\left(E_{r}^{\prime}\right)$. According to the percolation model, the modulus of the composite $E^{\prime}$ can be expressed by:

$$
E^{\prime}=\frac{\left(1-2 \psi+\psi X_{r}\right) E^{\prime}{ }_{s} E_{r}{ }_{r}+\left(1-X_{r}\right) \psi{E^{\prime}}_{r}{ }^{2}}{\left(1-X_{r}\right) E^{\prime}{ }_{r}+\left(X_{r}-\psi\right) E^{\prime}{ }_{s}}
$$

where $\psi$ is the percolation volume fraction of filler particles, which is:

$$
\psi=X_{r}\left(\frac{X_{r}-X_{c}}{1-X_{c}}\right)^{0.4}
$$

The critical concentration that the network starts to from is called the percolation threshold $\left(X_{c}\right)$, which it is related to the aspect ratio (AR) of the filler particles $\left(X_{c}=0.7 / \mathrm{AR}\right)$.

The values used for the prediction of storage modulus of $\mathrm{CNC} / \mathrm{P}(\mathrm{St}-\mathrm{co}-\mathrm{EHA})$ latex nanocomposites are: modulus of rigid filler $E_{r}^{\prime}=3 \mathrm{GPa}$, modulus of soft polymer matrix $E_{s}^{\prime}=$ $0.48 \mathrm{MPa}$, density of rigid filler $\rho=1.49 \mathrm{~g} / \mathrm{cm}^{3}$, density of polymer matrix $\rho=1.01 \mathrm{~g} / \mathrm{cm}^{3}$, aspect ratio of $\mathrm{m}-\mathrm{CNC} \mathrm{AR}=19$ and $\mathrm{MxG}-\mathrm{CNC} \mathrm{AR}=65$. 


\section{Coverage study:}

The theoretical coverage of CNCs at the particle surface can be calculated by:

$$
\text { coverage }=\frac{m_{p} D}{6 h \rho V}
$$

where $m_{p}$ is the amount of CNCs absorbed at the interface, $D$ is the average diameter of the latex particles, $h$ is the height of the CNCs (determined by AFM), $\rho$ is the density of the CNCs (1.49 $\mathrm{g} / \mathrm{cm}^{3}$ for both $\mathrm{CNCs}$ ), and $V$ is the volume of the monomer phase stabilized by CNCs. Assuming all the $\mathrm{CNC}$ were absorbed at the interface (which is the ideal case), for $m$-CNC $(\mathrm{h}=5.3 \mathrm{~nm})$, the coverage for 1, 2 and $3 \mathrm{wt} \%$ based on the average size from DLS are ca. 10, 27 and 34\%. For $M x G-\mathrm{CNC}(\mathrm{h}=3.4 \mathrm{~nm})$, the coverage for 1,2 and $3 \mathrm{wt} \%$ are ca. $19 \%, 38 \%, 53 \%$. In reality, the coverage number will probably be smaller since not all $\mathrm{CNC}$ will be absorbed at the interface. 

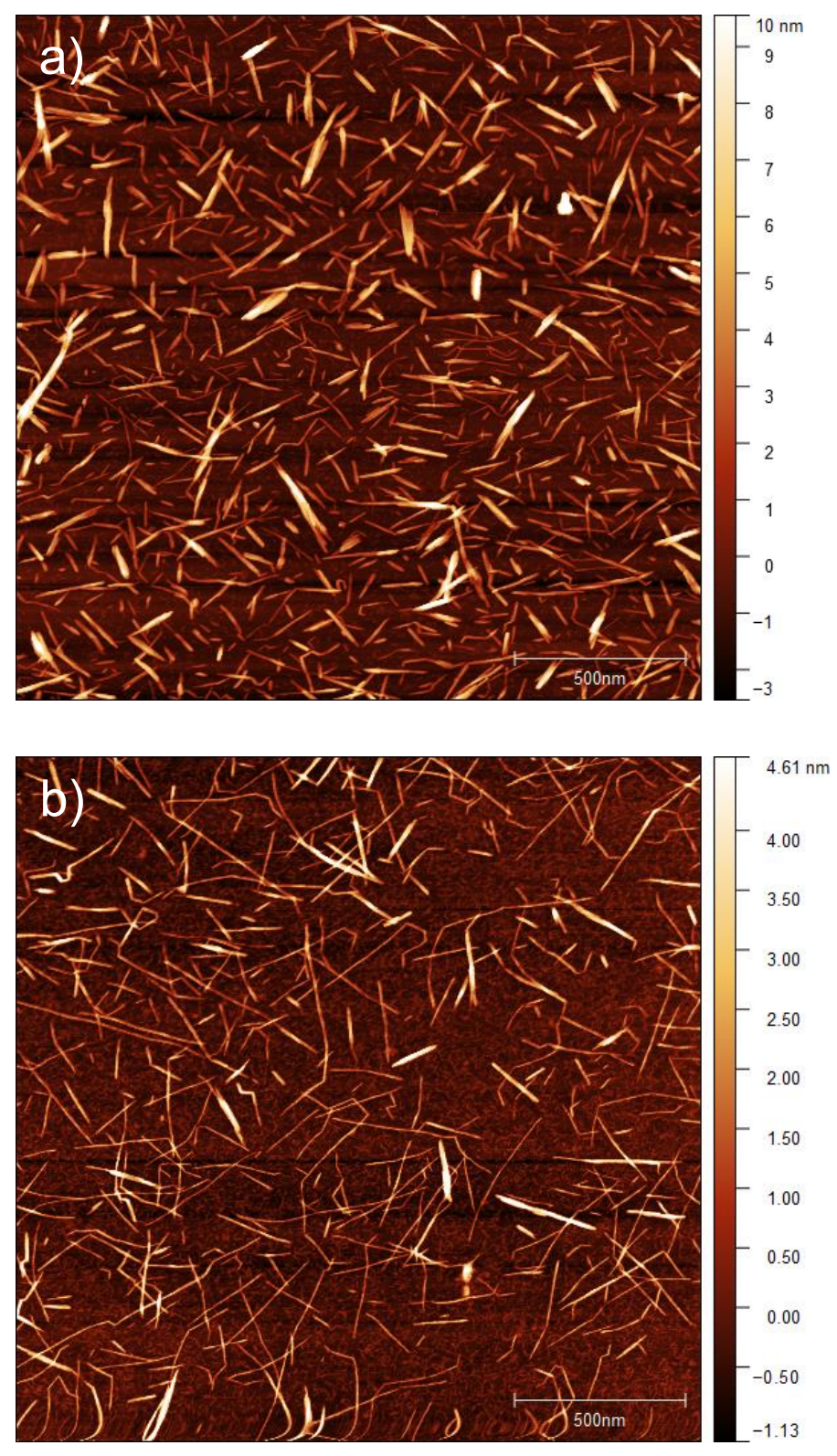

Fig S1. AFM height images of a) $m-\mathrm{CNC}-\mathrm{COOH}$ and b) $M x G-\mathrm{CNC}-\mathrm{COOH}$. 


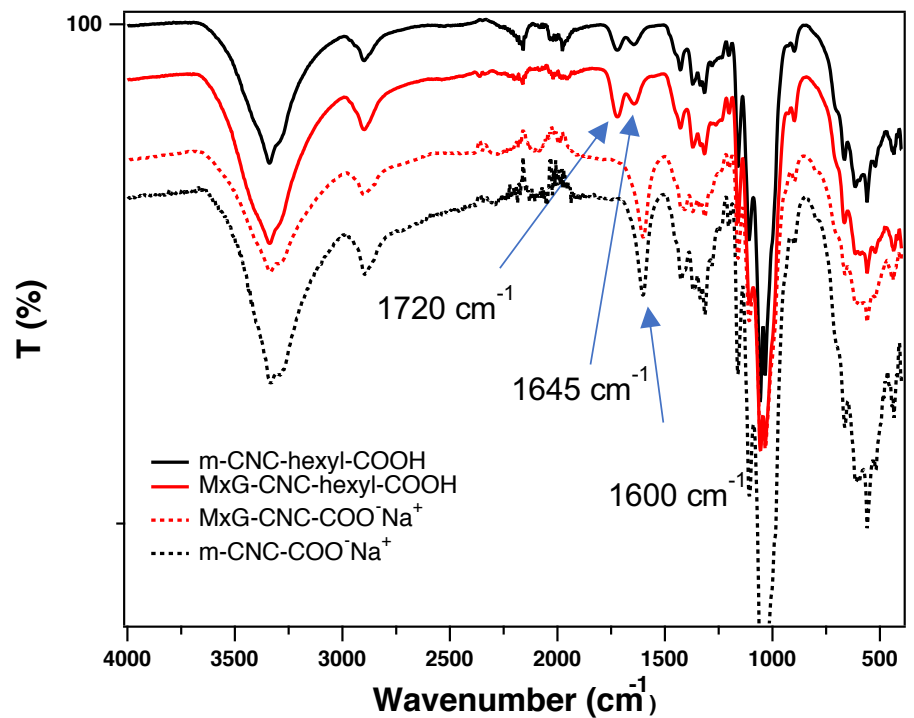

Fig S2. FTIR spectra of $m-\mathrm{CNC}$ and $M x G$-CNC after oxidation ( $m$-CNC-COO- $M x G$-CNC$\mathrm{COO}^{-}$), and after hydrophobic functionalization ( $m$-CNC-hexyl-COOH, $M x G$-CNC-hexyl$\mathrm{COOH})$. 
Table S1. Elemental analysis and zeta potential study of oxidized $m$-CNC-COOH and $M x G-$ $\mathrm{CNC}-\mathrm{COOH}$, and hydrophobic functionalized $m$-CNC-hexyl-COOH and $M x G$ - hexyl-CNC$\mathrm{COOH}$.

\begin{tabular}{ccccc}
\hline \multirow{2}{*}{ Sample } & \multicolumn{3}{c}{ Elemental Analysis } & Zeta Potential \\
\cline { 2 - 4 } & Carbon (\%) & Hydrogen (\%) & Nitrogen $(\%)$ & $(\mathrm{mV})$ \\
\hline$m$-CNC-COOH & 41.36 & 5.64 & 0.14 & $-79.7 \pm 1.3$ \\
$M x G$-CNC-COOH & 41.07 & 5.68 & not found & $-91.3 \pm 0.8$ \\
$m$-CNC-hexyl-COOH & 41.9 & 5.4 & 0.75 & $-55.5 \pm 0.8$ \\
$M x G$-CNC-hexyl-COOH & 41.48 & 5.71 & 1.03 & $-55.1 \pm 0.8$ \\
\hline
\end{tabular}



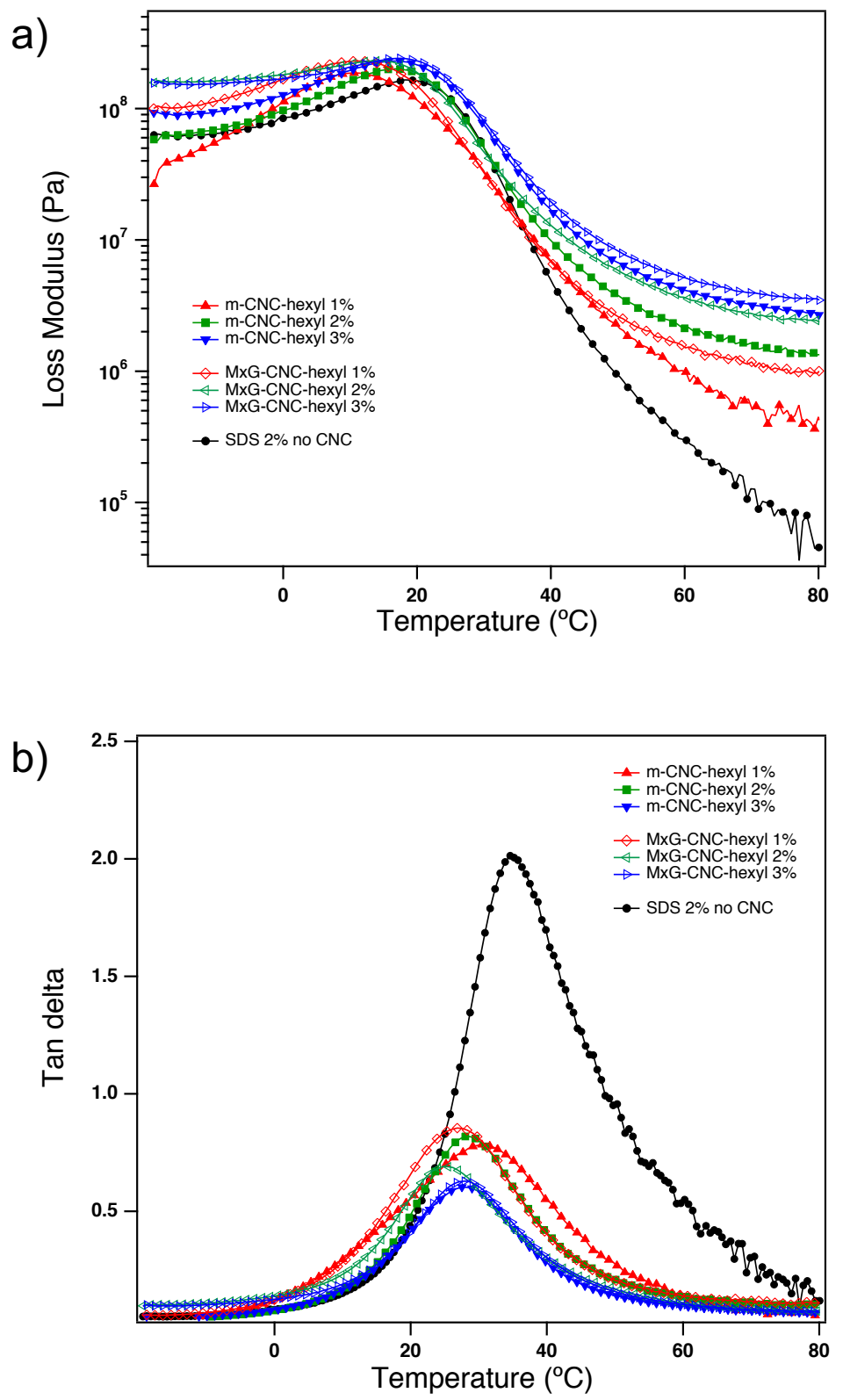

Fig S3. DMA temperature sweep study of the a) loss modulus $\left(E^{\prime \prime}\right)$ and b) $\tan \delta$ of the latex composite films stabilized with different type and concentration of stabilizers. 


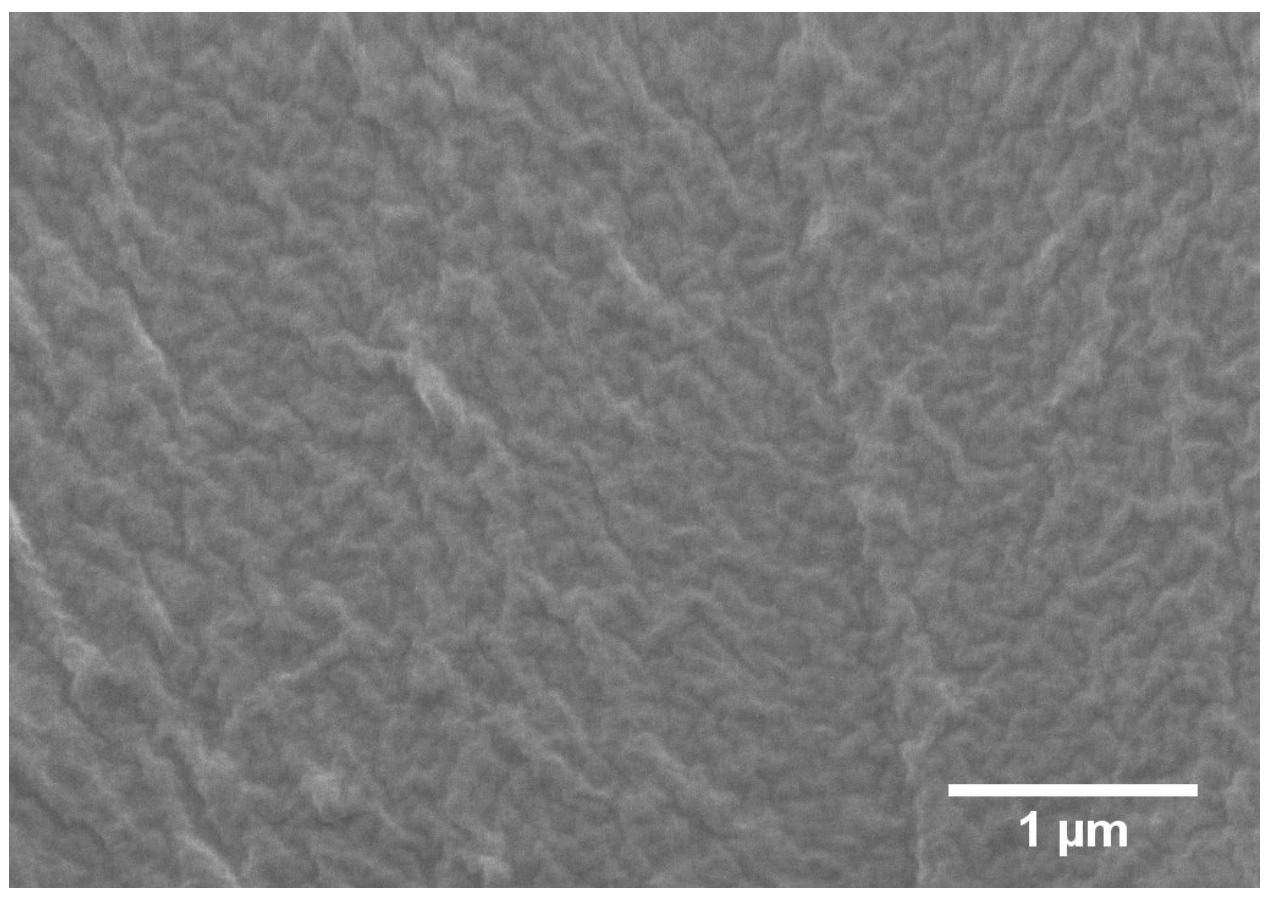

Fig S4. SEM images of the cross-sectional areas of latex films stabilized with SDS only. 

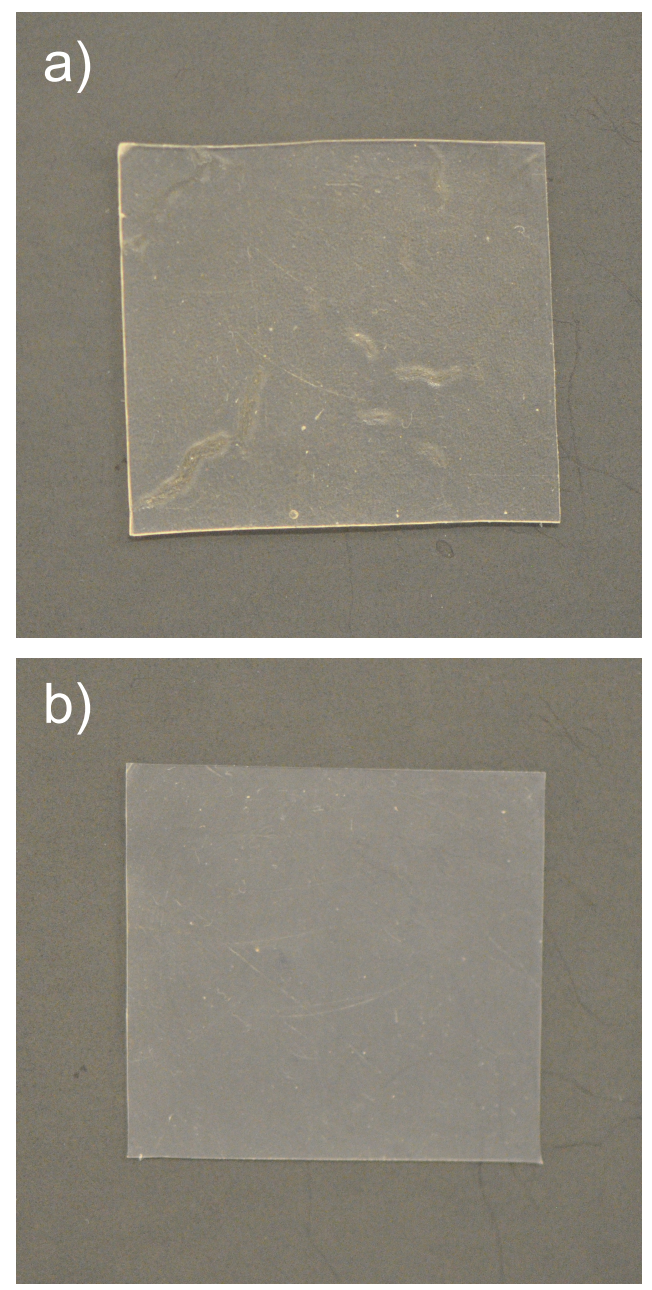

Fig S5. Latex composite films stabilized with SDS coated a) $m-\mathrm{CNC}-\mathrm{COOH}$ and b) $M x G-\mathrm{CNC}$ $\mathrm{COOH}$. 
Table S2. Comparison of the size of the latex particles and the mechanical properties and water swelling of the latex composite films stabilized with CNC-alkyl-COOH and CNC-COOH/SDS.

\begin{tabular}{|c|c|c|c|c|c|}
\hline Stabilizer & Concentration & SDS & Size (nm) & $\begin{array}{c}E^{\prime} \text { at } 60 \\
(\mathrm{MPa})\end{array}$ & $\begin{array}{c}\text { Water Swelling } \\
(\%)\end{array}$ \\
\hline$m$-CNC-hexyl-COOH & $2 \mathrm{wt} \%$ & 0 & $590.4 \pm 25.3$ & $17.1 \pm 1.7$ & 2.9 \\
\hline$m$-CNC-COOH & $2 \mathrm{wt} \%$ & $10 \mathrm{mM}$ & $172.9 \pm 10.5$ & $11.2 \pm 1.8$ & 35 \\
\hline$M x G-\mathrm{CNC}-\mathrm{hexyl-COOH}$ & $2 \mathrm{wt} \%$ & 0 & $541.0 \pm 7.2$ & $25.9 \pm 8.3$ & 3.2 \\
\hline$M x G-\mathrm{CNC}-\mathrm{COOH}$ & $2 \mathrm{wt} \%$ & $10 \mathrm{mM}$ & $165.6 \pm 8.0$ & $12.7 \pm 1.6$ & 49 \\
\hline
\end{tabular}



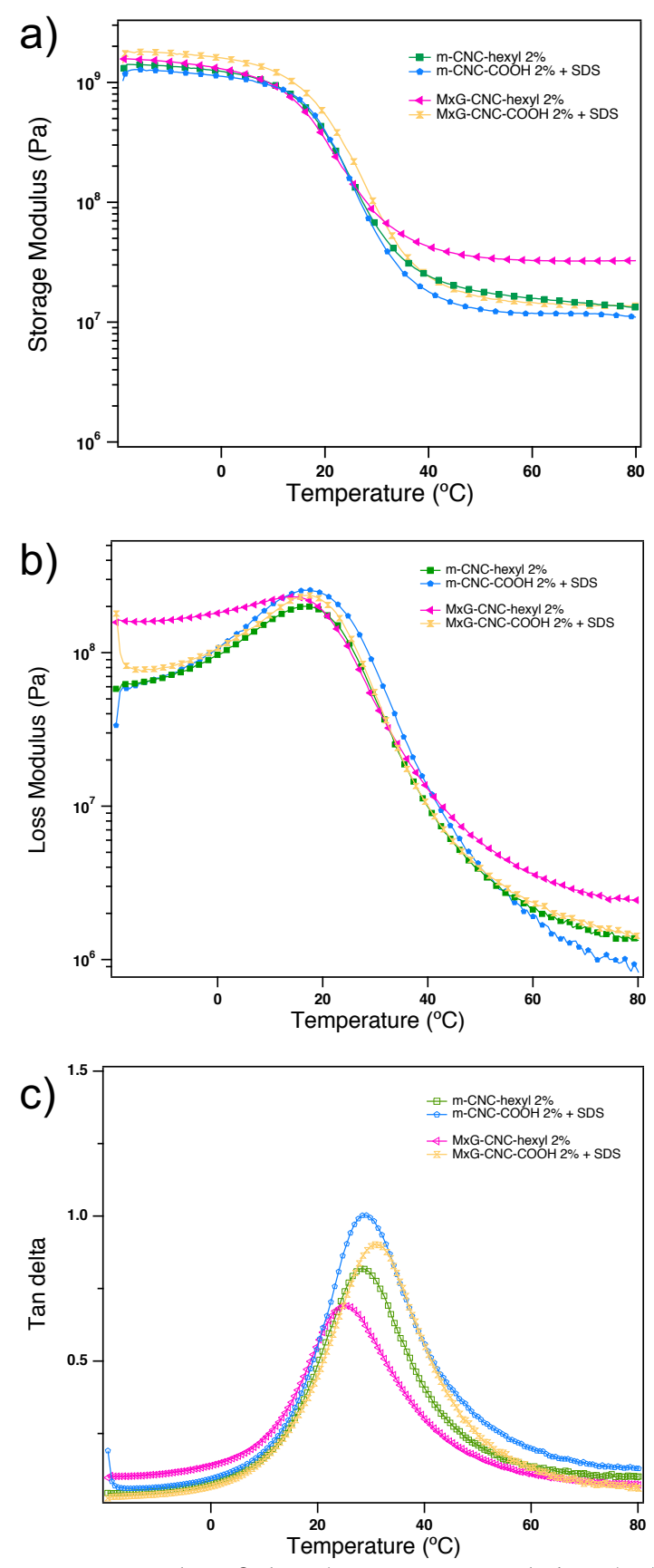

Fig S6. DMA temperature sweep study of the a) storage modulus $\left(E^{\prime}\right)$, b) loss modulus $\left(E^{\prime \prime}\right)$ and c) $\tan \delta$ of the latex composite films stabilized with SDS/m-CNC-COOH and SDS/MxG-CNC$\mathrm{COOH}$ compared to covalent functionalized $\mathrm{CNC}$-hexyl-COOH. 

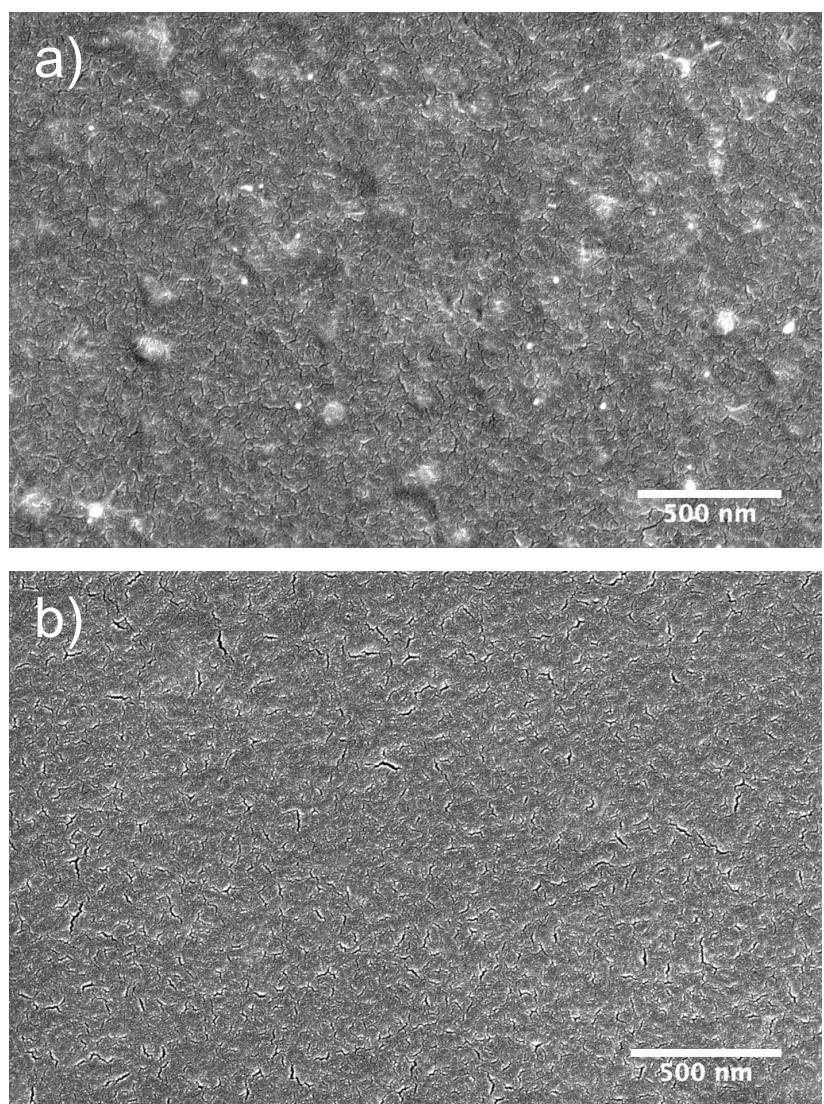

Fig S7. SEM images of the cross-sectional areas of latex composite films stabilized using SDS coated a) $2 \mathrm{wt} \% m-\mathrm{CNC}-\mathrm{COOH}$ and b) $2 \mathrm{wt} \% \mathrm{MxG}-\mathrm{CNC}-\mathrm{COOH}$. 

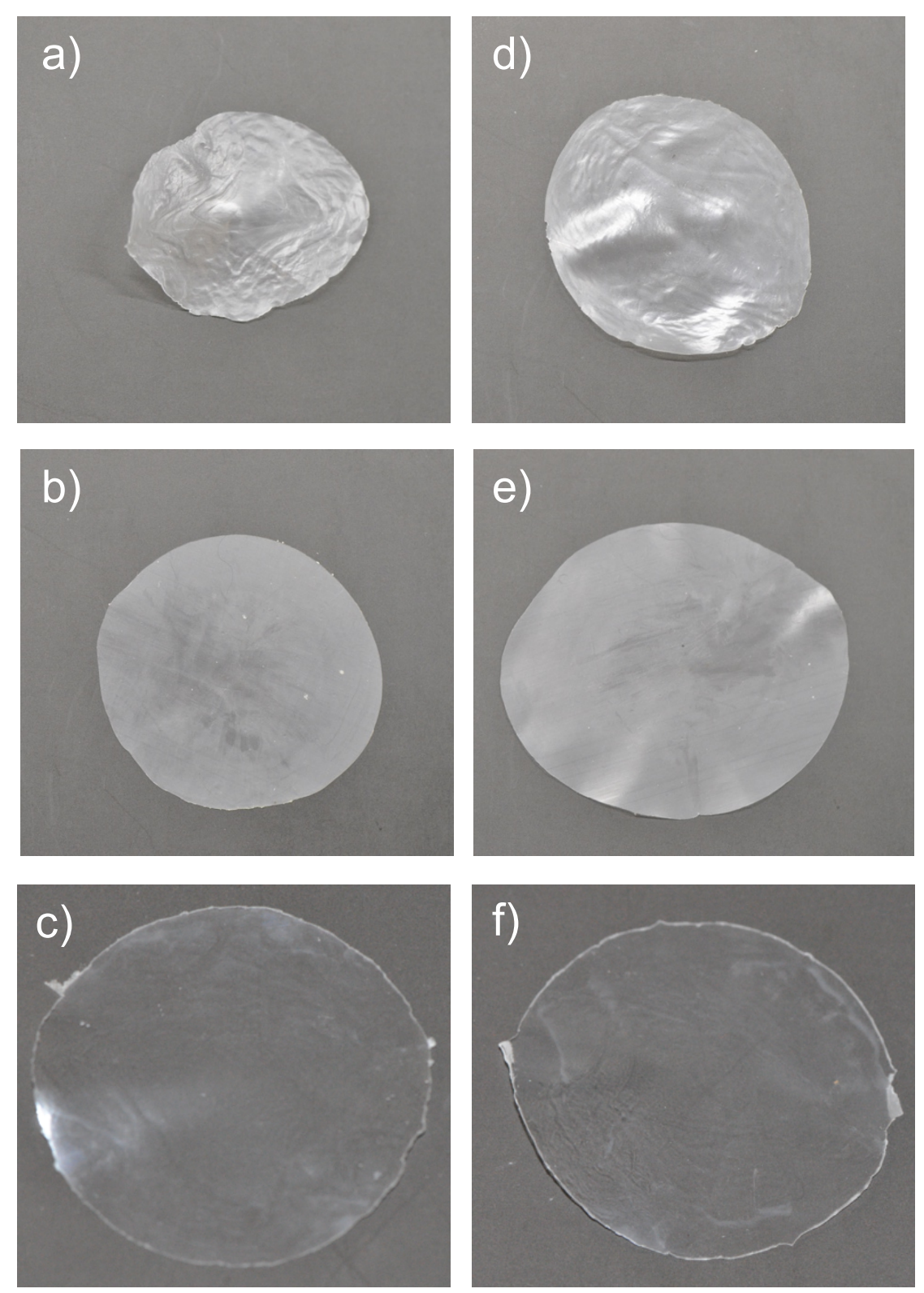

Fig S8. Melt-pressed latex nanocomposites stabilized by a) $1 \mathrm{wt} \%$, b) $2 \mathrm{wt} \%$, c) $3 \mathrm{wt} \%$ of $m$-CNChexyl-COOH and d) $1 \mathrm{wt} \%$, e) $2 \mathrm{wt} \%$, f) $3 \mathrm{wt} \%$ of $M x G$-CNC-hexyl-COOH. 

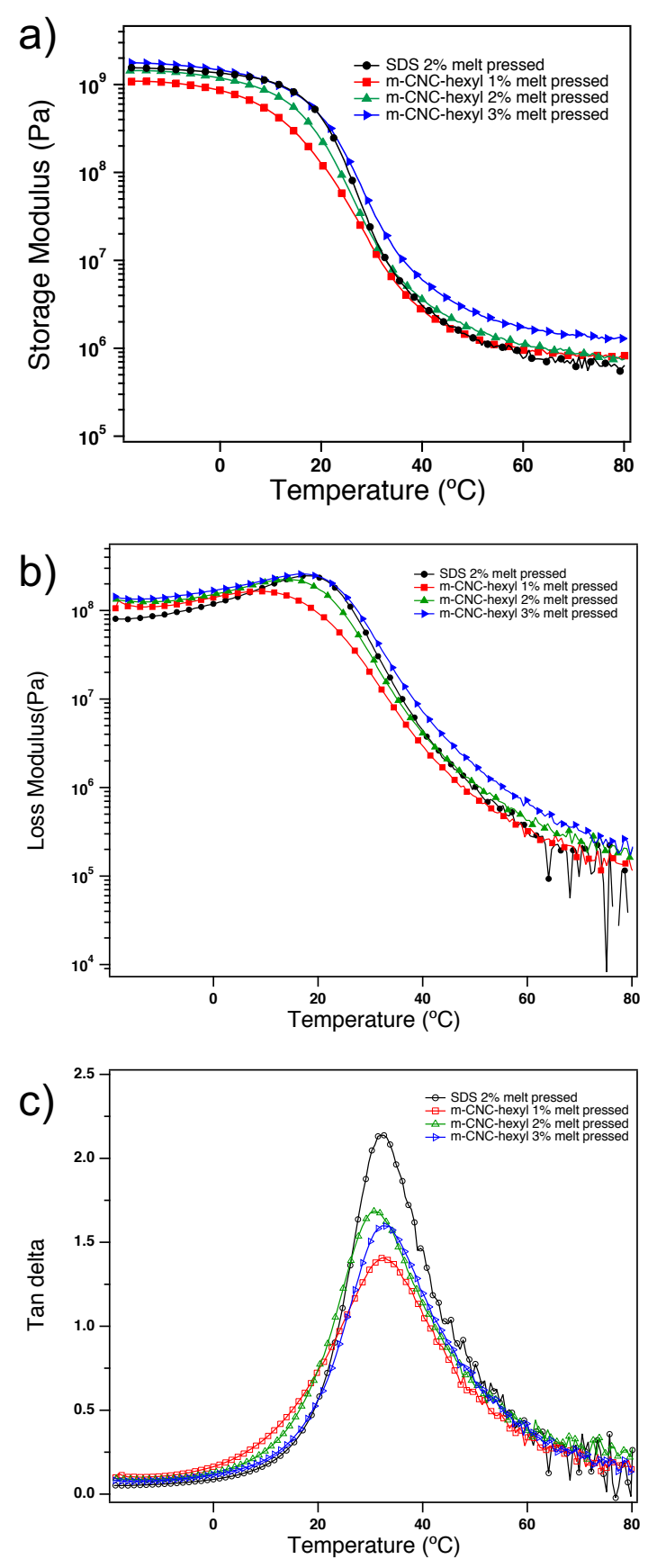

Fig S9. DMA temperature sweep study of the a) storage modulus $\left(E^{\prime}\right)$, b) loss modulus $\left(E^{\prime \prime}\right)$ and c) $\tan \delta$ of the latex composite films stabilized with SDS or $m$-CNC-hexyl-COOH after melt pressing. 

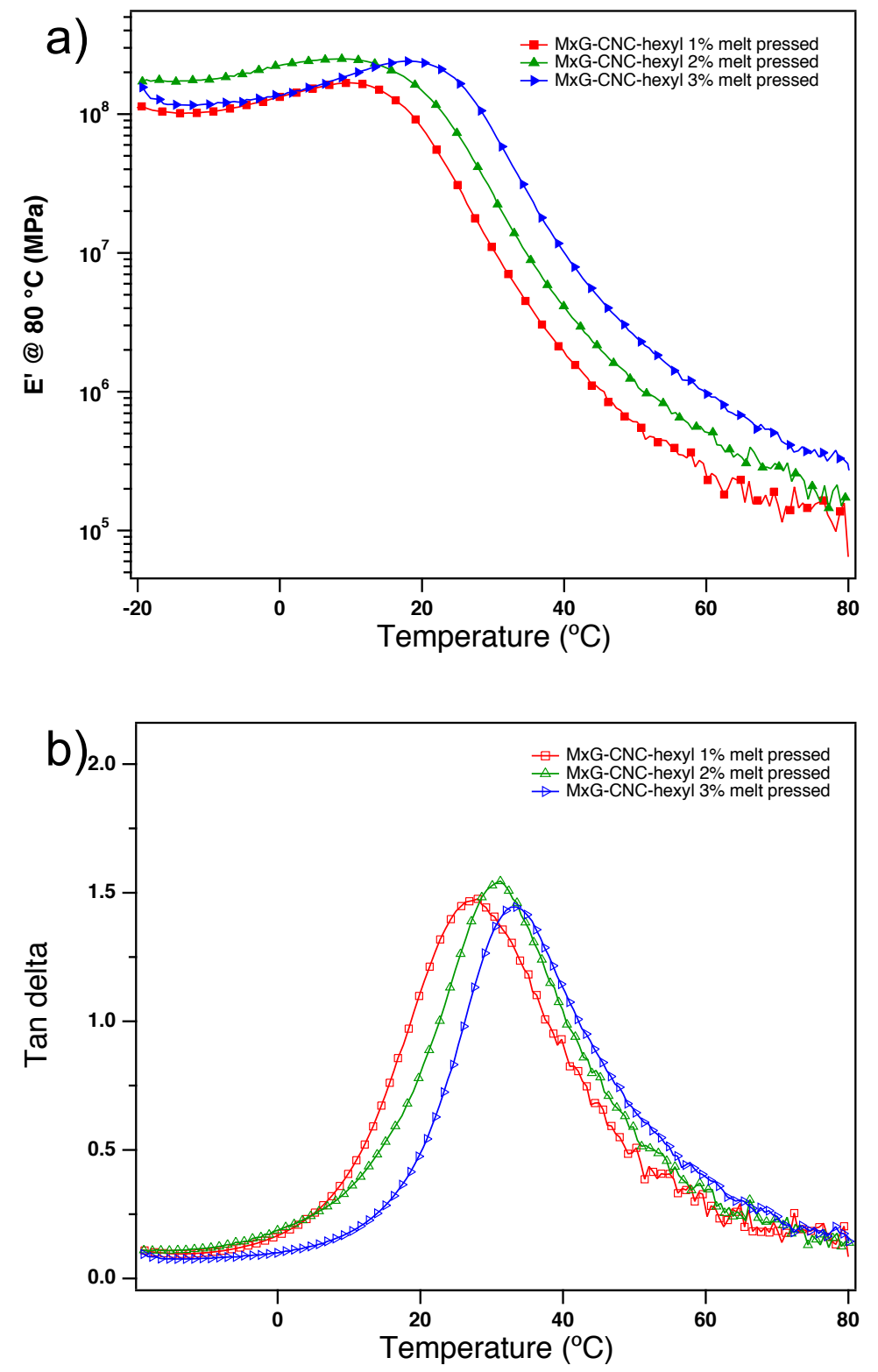

Fig S10. DMA temperature sweep study of the a) loss modulus $\left(E^{\prime \prime}\right)$ and b) tan $\delta$ of the latex composite films stabilized with $M x G$-CNC-hexyl-COOH after melt pressing. 

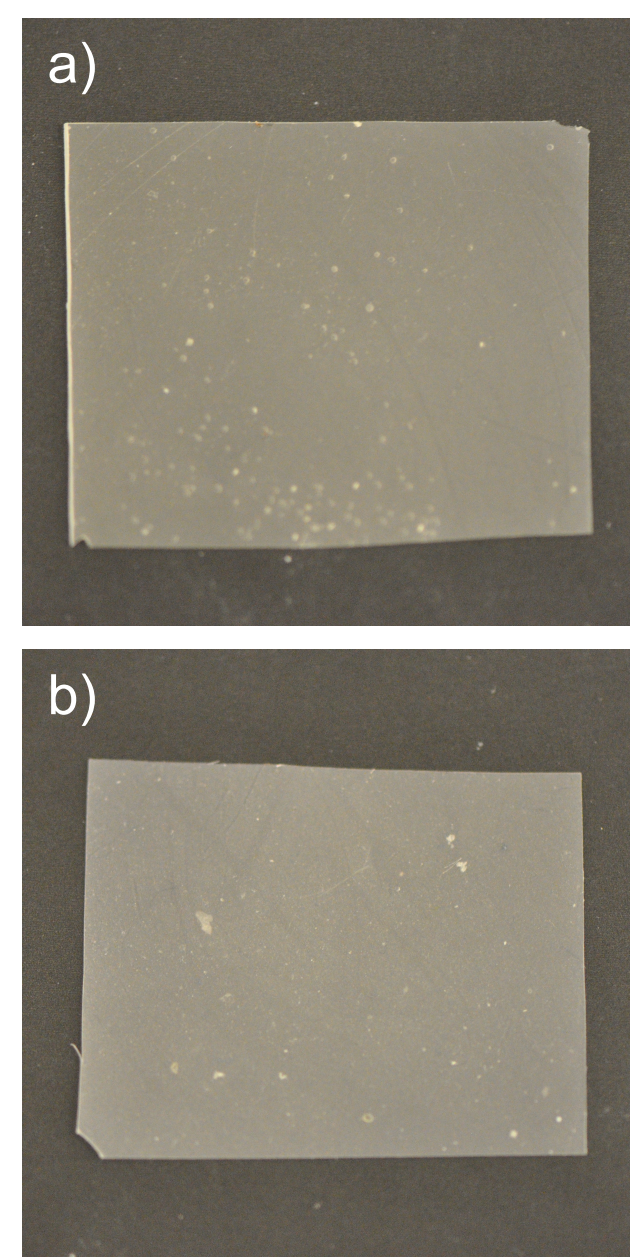

Fig S11. Latex composite films containing 13 wt.\% (10wt\% CNC-COOH and 3 wt.\% CNChexyl-COOH) of a) $m$-CNC and b) $M x G$-CNCs. 

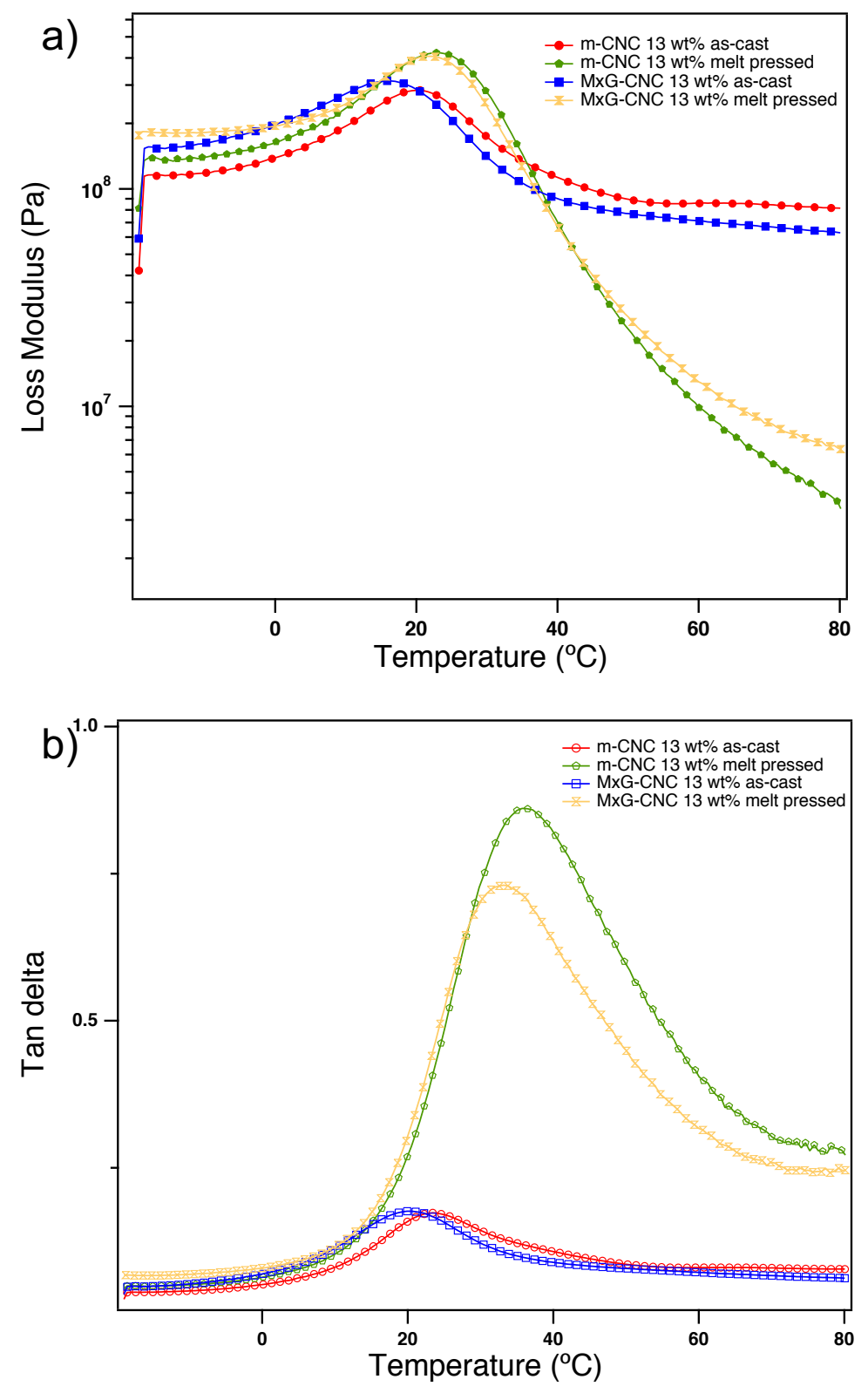

Fig S12. DMA temperature sweep study of the composite films containing $13 \mathrm{wt} . \%$ (10wt $\%$ $\mathrm{CNC}-\mathrm{COOH}$ and 3 wt.\% CNC-hexyl-COOH) $m$-CNC and $M x G$-CNC a) loss modulus ( $\left.E^{\prime \prime}\right)$ and b) $\tan \delta$ 
Reference:

(1) Favier, V.; Cavaille, J. Y.; Canova, G. R.; Shrivastava, S. C. Mechanical Percolation in Cellulose Whisker Nanocomposites. Polym. Eng. Sci. 1997, 37 (10), 1732-1739.

(2) Ouali, N.; Cavaille, J. Y.; Perez, J. Elastic, Viscoelastic and Plastic Behavior of Multiphase Polymer Blends. Plast. Rubber Compos. Process. Appl. 1991, 16 (1), 55-60. 